\title{
Total arterial revascularization with internal thoracic and radial artery grafts in triple-vessel coronary artery disease is associated with improved survival
}

\author{
Brian F. Buxton, FRACS, FRCSC, ${ }^{\mathrm{a}, \mathrm{b}}$ William Y. Shi, MBBS, ${ }^{\mathrm{b}}$ James Tatoulis, FRACS, ${ }^{\mathrm{a}, \mathrm{c}}$ \\ John A. Fuller, FRACP, ${ }^{a}$ Alexander Rosalion, FRACS, ${ }^{\mathrm{a}, \mathrm{b}}$ and Philip A. Hayward, FRCS, FRACS ${ }^{\mathrm{a}, \mathrm{b}}$
}

Objectives: We sought to evaluate our experience with total arterial revascularization and compare it with the traditional approach of a single internal thoracic artery supplemented by saphenous veins.

\begin{abstract}
Methods: From 1995 to 2010, 6059 patients with triple-vessel coronary artery disease underwent primary isolated coronary artery bypass grafting at 8 centers. A study cohort of 3774 patients was formed, with 2988 $(79 \%)$ undergoing total arterial revascularization and $786(21 \%)$ receiving only saphenous veins to supplement a single in situ internal thoracic artery. In the total arterial revascularization group, bilateral internal thoracic arteries were used in 1079 patients (36\%) and at least 1 radial artery was used in 2916 patients (97\%). Propensity score matching was used for risk adjustment.
\end{abstract}

Results: Patients undergoing total arterial revascularization were younger $(65.0 \pm 10.4$ years vs $71.3 \pm 7.9$ years, $P<.001)$ and less likely to have diabetes, cerebrovascular disease, recent myocardial infarction, and severe left ventricular impairment. At 15 years, patients who underwent total arterial revascularization experienced superior unadjusted survival $(62 \% \pm 1.1 \%$ vs $35 \% \pm 1.9 \%, P<.001)$. Multivariable Cox regression in the entire study cohort showed the total arterial group had improved survival with a hazard ratio of $0.79(95 \%$ confidence interval, $0.70-0.90 ; P<.001)$. After propensity score matching yielded 384 patient pairs, patients who underwent total arterial revascularization showed improved survival at 15 years than patients who underwent single arterial revascularization $(54 \% \pm 3.3 \%$ vs $41 \% \pm 3.0 \%, P=.0004)$.

Conclusions: This large multicenter study suggests that a strategy of total arterial revascularization is associated with improved long-term survival compared with the use of only a single arterial and saphenous vein grafts. Total arterial revascularization should be encouraged in patients with a reasonable life expectancy. (J Thorac Cardiovasc Surg 2014;148:1238-44)

Despite percutaneous coronary interventions becoming a feasible modality for coronary revascularization, coronary artery bypass grafting $(\mathrm{CABG})$ remains the standard of care for patients with 3 -vessel coronary disease. Although use of the left internal thoracic artery (LITA) has been shown to enhance survival, the impact of using arterial grafts exclusively on long-term survival is still debated.

In the past decade, there have been a number of studies showing the safety and feasibility of the right internal thoracic artery (RITA) and radial arteries (RAs) when

From the Victorian Heart Centre, ${ }^{\mathrm{a}}$ Epworth Hospital, University of Melbourne, Melbourne, Australia; Department of Cardiac Surgery, ${ }^{b}$ Austin Hospital, University of Melbourne, Melbourne, Australia; and Department of Cardiothoracic Surgery, ${ }^{\mathrm{c}}$ Royal Melbourne Hospital, Melbourne, Australia.

Disclosures: Authors have nothing to disclose with regard to commercial support.

Read at the 94th Annual Meeting of The American Association for Thoracic Surgery, Toronto, Ontario, Canada, April 26-30, 2014.

Received for publication April 26, 2014; revisions received June 20, 2014; accepted for publication June 27, 2014; available ahead of print Aug 15, 2014.

Address for reprints: Brian F. Buxton, FRACS, FRCSC, Department of Cardiac Surgery, University of Melbourne, Austin Hospital, Melbourne, Victoria 3084, Australia (E-mail: brianbuxton40@gmail.com).

$0022-5223 / \$ 36.00$

Copyright (c) 2014 by The American Association for Thoracic Surgery

http://dx.doi.org/10.1016/j.jtcvs.2014.06.056 used to supplement the LITA. ${ }^{1-7}$ The patency of these conduits is at least equivalent to, if not superior to, that of the saphenous vein (SV). ${ }^{3,5,6}$

Given the patency and biology of arterial conduits, there is speculation that their extensive use may translate to improved long-term survival. As such, we sought to evaluate our experience with total arterial revascularization (TAR) using internal thoracic arteries (ITAs) and RAs and compare it with the traditional approach of just a single internal thoracic artery (SITA) supplemented by SVs $($ SITA + SV) in patients with 3-vessel coronary artery disease.

\section{METHODS}

We reviewed a multicenter database containing a total of 23,343 adult coronary artery procedures performed from March 1, 1977, to December 31, 2010, across 8 centers affiliated with the University of Melbourne, Australia. These were Austin, Cabrini, Epworth Richmond, Epworth Eastern, Knox, Royal Melbourne, St Vincent's Melbourne, and Warringal Hospitals.

The database records detailed patient demography, preoperative risk factors, operative technique, postoperative hospital course, and clinical outcome including in-hospital morbidity and 30-day mortality. Data were collected prospectively. Survival status of patients was obtained from the Australian National Death Index, which records all deaths within Australia, the censoring date for which was April 30, 2013. ${ }^{8}$ 

Abbreviations and Acronyms
BITA = bilateral internal thoracic artery
$\mathrm{CABG}=$ coronary artery bypass grafting
ITA = internal thoracic artery
LAD $=$ left anterior descending
LITA = left internal thoracic artery
RA $=$ radial artery
RITA = right internal thoracic artery
SITA = single internal thoracic artery
$\mathrm{SV}=$ saphenous vein
$\mathrm{TAR}=$ total arterial revascularization

\section{Study Sample}

Patients were included for analysis if they had 3-vessel coronary disease, underwent primary isolated nonemergency $\mathrm{CABG}$, and received at least 1 in situ ITA. Patients were excluded if they received any other conduits, such as the gastroepiploic artery, ulnar artery, or cephalic vein, because these conduits have never been incorporated into routine clinical use during the time period.

Three-vessel disease was defined as 3 coronary systems each with greater than or equal to $60 \%$ stenosis in any angiographic view (left main stenosis $>60 \%$ was counted as 2 systems, the left anterior descending [LAD] and circumflex, such that left main and right coronary disease was considered 3 -vessel disease). Stenosis was graded as $0 \%$ to $19 \%, 20 \%$ to $39 \%, 40 \%$ to $59 \%, 60 \%$ to $79 \%, 80 \%$ to $99 \%$, or total occlusion. This meant the traditional cutoff of $50 \%$ for left main-stem disease could not be applied.

We selected patients undergoing surgery since January 1995, because this coincided with the introduction of the RA conduits into routine clinical practice, permitting TAR to be achieved in combination with the LITA and RITA.

Within these data, we identified the subgroup undergoing TAR, whereby patients received at least 1 in situ ITA supplemented by an additional in situ or free ITA or RAs. The SITA and SV group (SITA + SV) was identified as those receiving 1 in situ ITA supplemented by SVs only. Patients who received a mixture of both arterial and venous conduits to supplement a SITA (ie, LITA + RA + SV, bilateral internal thoracic artery [BITA] + $\mathrm{SV}$ configurations) were excluded.

A total of 6059 patients underwent operation for 3-vessel coronary artery disease during the study period. Of these, 2285 received a mixture of both arterial and venous conduits to supplement a SITA and thus were excluded. As such, 3774 patients were ultimately included for analysis, with $2988(79 \%)$ in the TAR group and $786(21 \%)$ in the SITA + SV group.

\section{Study End Points}

We examined early outcomes, which included 30-day mortality, deep sternal wound infection, conduit harvest site infection, postoperative myocardial infarction, postoperative stroke, return to the operating room for bleeding, acute renal impairment ( \pm requirement for dialysis), and a composite end point of "any adverse event" that encompasses the events listed. Furthermore, we examined long-term survival using data from the National Death Index. ${ }^{8}$

\section{Surgical Technique}

All patients underwent median sternotomy. The ITAs were harvested as a pedicle or in a skeletonized fashion, the latter being performed after the year 2000. ITAs and RAs were prepared with a solution of Ringer's Lactate and papaverine $1 \mathrm{mmol} / \mathrm{L}(40 \mathrm{mg} / 100 \mathrm{~mL})$. Most procedures were performed with a standard cardiopulmonary bypass using a combination of antegrade and retrograde cardioplegia.

In the TAR cohort, a number of different graft configurations were used. In certain patients, the use of sequential anastomoses permitted more than 1 distal anastomosis to be achieved for a given conduit. Composite " $Y$ " grafts were used to enhance flexibility and were recorded in the database as 2 separate conduits creating 2 distal anastomoses.

When a LITA was used $(n=2978)$, it was grafted to the LAD territory in 2621 patients $(88 \%)$ and the circumflex system in the remaining 357 patients $(12 \%)$. A sequential anastomosis to the diagonal territory using the LITA was performed in 619 patients $(21 \%)$ as part of a LITAdiagonal-LAD configuration, making a total of 3597 distal anastomoses using the LITA.

A RITA was used in 1089 cases. It was used as an in situ conduit in 554 patients $(51 \%)$ and as a free graft in the remainder. In 10 patients, a RITA was used instead of a LITA. Altogether, 1079 patients received the RITA as part of a BITA strategy. By taking into account 42 sequential anastomoses, a total of 1131 distal anastomoses were performed with the RITA. These were performed to the LAD artery in 235 patients $(22 \%)$, the diagonal artery in 136 patients $(12 \%)$, the circumflex artery in 371 patients $(34 \%)$, and the right coronary artery in 389 patients $(36 \%)$.

At least 1 RA was used in 2916 patients (98\%). A single RA was used in 1507 patients, whereas bilateral RAs were used in 1409 patients such that a total of 4325 RA conduits were used. Preference was given to the proximal anastomosis of the RA with the aorta rather than the LITA because of a potential size mismatch with and for protection of the LITA to LAD graft. By taking into account 533 sequential anastomoses, a total of 4858 distal anastomoses were performed with the RA. Of these, 646 (13\%) were to the diagonal artery, $2017(42 \%)$ were to the circumflex artery, and 2195 $(45 \%)$ were to the right coronary artery.

\section{Statistical Analysis}

Preoperative demographic and investigative data, operative variables, postoperative (30-day) mortality, morbidity, and 15-year survival were compared between the TAR and SITA + SV groups.

Categoric variables were expressed as frequencies and compared using the Fisher exact and chi-square tests. Continuous variables were expressed as mean \pm standard deviation and compared using the unpaired $t$ test. The Kaplan-Meier method was used to analyze survival. Multivariable logistic regression and Cox regression, both performed in a backward elimination fashion, were used to identify independent predictors of early and late outcomes, respectively. The backward elimination method was used to include all potential predictors of end points in the initial models and subsequently eliminate covariates in an iterative process to create a final model. Inclusion of all potentially important variables in the initial model allows their joint predictive behavior to be initially evaluated, which is important given that a set of variables may exhibit predictive capability even if a subset does not.

Propensity score matching was performed to correct for the bias associated with the use of TAR. A propensity score was generated for each patient in the standard fashion by performing a logistic regression with the grafting strategy as the dependent variable. Baseline clinical and investigative variables that are expected to influence cardiac surgery patient outcomes were included. These are shown in Table 1 . The c-statistic was calculated for the propensity model. Once this was generated, patients were matched 1 to 1 on their propensity score without replacement using the "greedy" matching method with a fixed caliper width of 0.05 . A caliper width of 0.05 was selected to ensure a close match with respect to covariates while also minimizing the number of subjects excluded from matching.

After matching, standardized differences were used to assess the degree of baseline variable balance in the manner described by Austin. ${ }^{9}$ A high degree of balance is reflected by a standardized difference of $10 \%$ or less. Standardized differences were calculated for the entire nonmatched population and to aid reader identification of imbalanced baseline variables. 
TABLE 1. Selected preoperative clinical, investigative profile, intraoperative, and early postoperative outcomes

\begin{tabular}{|c|c|c|c|c|}
\hline Variable & $\begin{array}{c}\text { SITA + SV } \\
(n=786)\end{array}$ & $\begin{array}{c}\text { TAR } \\
(\mathbf{n}=\mathbf{2 9 8 8})\end{array}$ & $\begin{array}{c}P \\
\text { value }\end{array}$ & $\begin{array}{c}\text { Standardized } \\
\text { difference }\end{array}$ \\
\hline Age (y) & $71.3 \pm 7.9$ & $65.0 \pm 10.4$ & $<.001$ & -68.2 \\
\hline$<60$ & $78(10)$ & 993 (33) & - & 59.1 \\
\hline $60-70$ & $249(32)$ & $998(33)$ & - & 3.7 \\
\hline $71-80$ & $381(48)$ & $817(27)$ & - & -44.6 \\
\hline$>81$ & $76(10)$ & $176(6)$ & $<.001$ & -14.1 \\
\hline Missing & $2(0)$ & $4(0)$ & - & -2.7 \\
\hline Male & $593(75)$ & $2416(81)$ & .001 & 13.1 \\
\hline \multicolumn{5}{|l|}{ Time period } \\
\hline $1995-2000$ & $588(75)$ & $1553(52)$ & - & -48.8 \\
\hline $2001-2005$ & 134 (17) & $955(32)$ & - & 35.2 \\
\hline $2006-2010$ & $64(8)$ & $480(16)$ & $<.001$ & 24.5 \\
\hline Hypertension & $481(61)$ & $1754(59)$ & .22 & -5.1 \\
\hline Diabetes & 267 (34) & $714(24)$ & $<.001$ & -22.4 \\
\hline Diabetes - on insulin & $54(7)$ & $145(5)$ & .031 & -8.6 \\
\hline Cerebrovascular disease & $118(15)$ & $253(8)$ & $<.001$ & -20.4 \\
\hline $\begin{array}{l}\text { Peripheral vascular } \\
\text { disease }\end{array}$ & $80(10)$ & $230(8)$ & .028 & -8.7 \\
\hline Previous AMI & $430(55)$ & $1355(45)$ & $<.001$ & -18.8 \\
\hline AMI within $7 \mathrm{~d}$ & $122(16)$ & $283(9)$ & $<.001$ & -18.4 \\
\hline Previous PCI & $22(3)$ & $266(9)$ & $<.001$ & 26.2 \\
\hline Nonelective case & $182(23)$ & $691(23)$ & $>.99$ & -0.1 \\
\hline Active smoking & $126(16)$ & $603(20)$ & .008 & 10.8 \\
\hline Nonsmoker & 297 (38) & $1203(40)$ & .22 & 5.1 \\
\hline Dialysis preoperatively & $9(1)$ & $11(0)$ & .022 & -9.0 \\
\hline COPD & $26(3)$ & $114(4)$ & 6 & 2.7 \\
\hline \multicolumn{5}{|l|}{ LVEF } \\
\hline$>65 \%$ & $186(24)$ & $864(29)$ & - & 12.0 \\
\hline $50 \%-65 \%$ & $259(33)$ & $1246(42)$ & - & 18.2 \\
\hline $30 \%-49 \%$ & $243(31)$ & $681(23)$ & - & -18.4 \\
\hline$<30 \%$ & $62(8)$ & $89(3)$ & $<.001$ & -21.8 \\
\hline Missing & $36(5)$ & $108(4)$ & - & - \\
\hline Left main $>60 \%$ & $204(26)$ & 559 (19) & $<.001$ & -17.5 \\
\hline No. of anastomoses & $3.5 \pm 0.8$ & $3.4 \pm 0.8$ & .075 & -12.5 \\
\hline 2 & $52(7)$ & $289(10)$ & - & 11.2 \\
\hline 3 & $393(50)$ & $1487(50)$ & - & -0.5 \\
\hline$>3$ & $341(43)$ & $1212(41)$ & .064 & -5.7 \\
\hline Intraoperative & $\begin{array}{c}\text { SITA + SV } \\
(\mathbf{n}=786)\end{array}$ & $\begin{array}{c}\text { TAR } \\
(\mathbf{n}=\mathbf{2 9 8 8})\end{array}$ & $\begin{array}{c}P \\
\text { value }\end{array}$ & \\
\hline Bypass time & $103.8 \pm 34.1$ & $98.8 \pm 40.0$ & .051 & \\
\hline Crossclamp time & $73.6 \pm 23.7$ & $75.8 \pm 24.1$ & .031 & \\
\hline Early outcomes & $\begin{array}{c}\text { SITA + SV } \\
(n=786)\end{array}$ & $\begin{array}{c}\text { TAR } \\
(n=2988)\end{array}$ & $\begin{array}{c}P \\
\text { value }\end{array}$ & \\
\hline 30-d mortality & $25(3.2)$ & $40(1.3)$ & .001 & \\
\hline Sternal infection & $10(1.3)$ & $30(1)$ & .56 & \\
\hline Harvest site infection & $13(1.7)$ & $18(0.6)$ & .007 & \\
\hline Postoperative AMI & $11(1.4)$ & $15(0.5)$ & .013 & \\
\hline Postoperative stroke & $8(1)$ & $19(0.6)$ & .24 & \\
\hline Return for bleeding & $20(2.5)$ & $58(1.9)$ & .32 & \\
\hline $\begin{array}{l}\text { Renal impairment or } \\
\text { dialysis }\end{array}$ & $18(2.3)$ & $61(2)$ & .68 & \\
\hline Any adverse event & $90(11.5)$ & $199(6.7)$ & $<.001$ & \\
\hline
\end{tabular}

In the matched sample, paired $t$ tests were used for continuous data and McNemar's test, which compares discordance of 2 dichotomous outcomes, was used to compare categoric postoperative outcomes. Among the matched pairs, the test proposed by Klein and Moeschberger was used to compare survival. ${ }^{9}$

\section{RESULTS}

The preoperative clinical profile of the study population is presented in Table 1. A number of comorbidities were more prevalent in the SITA + SV group. These included older age, diabetes mellitus, cerebrovascular disease, and severe left ventricular dysfunction. Of note, 341 patients received only 2 anastomoses, leaving at least 1 ungrafted territory.

Intraoperatively, patients undergoing TAR experienced shorter cardiopulmonary bypass pump and aortic crossclamp times versus patients undergoing SITA + SV. Early postoperative outcomes are presented in Table 1. Of note, patients in the TAR group experienced reduced unadjusted 30 -day mortality $(1.3 \%$ vs $3.2 \%$, $P=.001)$.

Survival data from the National Death Index were available with a mean of $10.0 \pm 4.8$ years (range, $0-18.3$ years). Figure 1 displays the Kaplan-Meier survival analysis, which suggests a superior unadjusted 15 -year survival in the TAR group versus the SITA + SV group $(62 \% \pm$ $1.1 \%$ vs $35 \% \pm 1.9 \%, P>.0001)$.

Multivariable analysis showed no statistically significant association between TAR and SITA + SVs in 30-day mortality (odds ratio, $0.75 ; 95 \%$ confidence interval, 0.43-1.30). However, TAR was associated with a reduced risk of late mortality on multivariable Cox regression (hazard ratio, 0.79; 95\% confidence interval, 0.70-0.90; $P<.001$ ), as shown in Table 2.

The propensity score model performed well with a c-statistic of 0.825 . We matched 384 patients undergoing

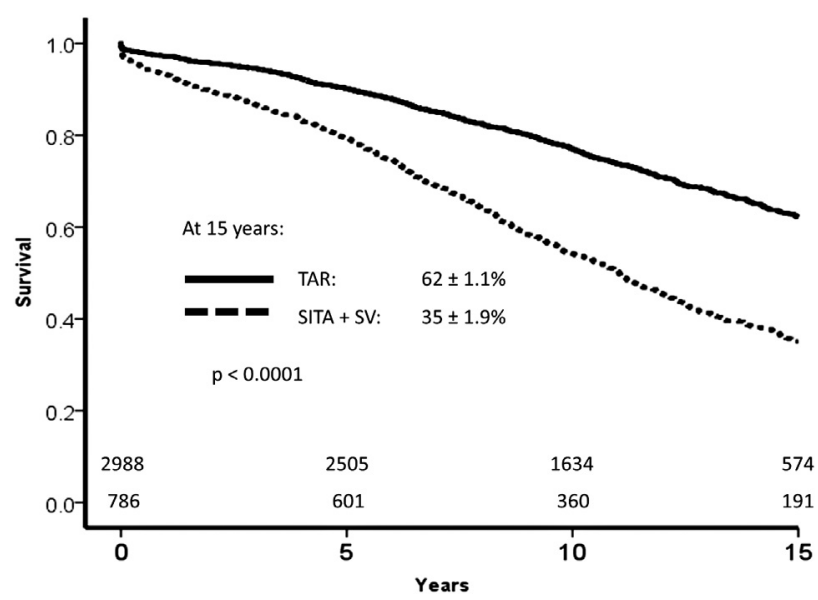

FIGURE 1. Unadjusted 15-year survival. SITA, Single internal thoracic artery; $S V$, saphenous vein; $T A R$, total arterial revascularization. 
TABLE 2. Logistic and Cox regressions for early and late outcomes for patients undergoing total arterial revascularization

\begin{tabular}{lcccc}
\hline & $\begin{array}{c}\text { Odds } \\
\text { ratio }\end{array}$ & $\begin{array}{c}\mathbf{9 5 \%} \text { CI } \\
\text { (lower) }\end{array}$ & $\begin{array}{c}\text { 95\% CI } \\
\text { (upper) }\end{array}$ & $\boldsymbol{P}$ value \\
\hline 30-d mortality & 0.75 & 0.43 & 1.30 & .30 \\
Any early adverse event & 0.84 & 0.62 & 1.15 & .28 \\
\hline & Hazard & $\mathbf{9 5 \%}$ CI & $\mathbf{9 5 \%}$ CI & \\
& ratio & (lower) & (upper) & $\boldsymbol{P}$ value \\
\hline Follow-up mortality & 0.79 & 0.70 & 0.90 & $<.001$ \\
\hline$C I$, Confidence interval. & & & &
\end{tabular}

TAR to 384 patients undergoing SITA + SV, representing a $49 \%$ matching rate. Of 24 baseline variables, 23 were well balanced with a standardized difference of $10 \%$ or less (Table 3). The mean standardized difference after propensity score matching was $4.4 \% \pm 3.4 \%$ compared with $17.4 \% \pm 16.3 \%$ before matching.

After propensity score matching, there were no statistically significant differences in intraoperative and early postoperative outcomes (Table 3). However, survival analysis in the matched samples showed that those receiving TAR experienced improved survival compared with those receiving SITA + SV at 15 years $(54 \% \pm 3.3 \%$ vs $41 \% \pm 3.0 \%, P=.0003)$ (Figure 2$)$.

\section{DISCUSSION}

This large multicenter analysis directly compares a strategy of TAR using ITAs and RAs with the more traditional approach of a SITA supplemented by SVs $($ SITA + SV). The latter is the most commonly performed procedure worldwide.

Our data suggest that during this period, there was a strong selection bias toward sicker, more unstable patients receiving SITA and SVs only. This reflects the greater time required for harvesting arterial conduits and their perceived risk of increasing perioperative risks, especially that of BITAs. Not surprisingly, the unadjusted early and late survival favors those undergoing TAR. Nevertheless, the association between TAR and improved long-term survival existed in multivariable regression and propensity score matched analyses.

Long-term survival after CABG may be related to the late patency of conduits, and this may partially explain the improved survival seen with TAR in this and other studies. There are randomized data emerging to suggest that RAs exhibit superior patency compared with veins, ${ }^{3}$ and although there are few data directly comparing RITA and $\mathrm{SVs}$, it is perhaps the perceived increased risk of deep sternal wound infection associated with RITA use that limits its use. ${ }^{10,11}$
TABLE 3. Selected clinical investigative profile, intraoperative and early postoperative outcomes of propensity score matched cases

\begin{tabular}{|c|c|c|c|c|}
\hline $\begin{array}{c}\text { Preoperative } \\
\text { variable }\end{array}$ & $\begin{array}{c}\text { SITA + SV } \\
(\mathbf{n}=384)\end{array}$ & $\begin{array}{c}\text { TAR } \\
(\mathbf{n}=\mathbf{3 8 4})\end{array}$ & $\begin{array}{c}P \\
\text { value }\end{array}$ & $\begin{array}{c}\text { Standardized } \\
\text { difference }\end{array}$ \\
\hline Age, y & $69.7 \pm 8.7$ & $70.3 \pm 8.6$ & .28 & 6.5 \\
\hline$<60$ & $56(15)$ & $45(12)$ & - & -8.5 \\
\hline $60-70$ & $135(35)$ & $140(36)$ & - & 2.7 \\
\hline $71-80$ & $155(40)$ & $162(42)$ & - & 3.7 \\
\hline$>81$ & $38(10)$ & $37(10)$ & .52 & -0.9 \\
\hline Male & $302(79)$ & $292(76)$ & .44 & -6.2 \\
\hline \multicolumn{5}{|l|}{ Time period } \\
\hline $1995-2000$ & $232(60)$ & $219(57)$ & - & -6.9 \\
\hline 2001-2005 & $108(28)$ & $108(28)$ & - & 0.0 \\
\hline 2006-2010 & $44(11)$ & $57(15)$ & .53 & 10.0 \\
\hline Hypertension & $238(62)$ & $225(59)$ & .38 & -6.9 \\
\hline Diabetes & $109(28)$ & $104(27)$ & .75 & -2.9 \\
\hline Diabetes - on insulin & $25(7)$ & $27(7)$ & .89 & 2.1 \\
\hline Cerebrovascular disease & $42(11)$ & $42(11)$ & $>.99$ & 0.0 \\
\hline $\begin{array}{l}\text { Peripheral vascular } \\
\text { disease }\end{array}$ & $39(10)$ & $37(10)$ & .9 & -1.7 \\
\hline Previous AMI & $180(47)$ & $172(45)$ & .61 & -4.2 \\
\hline AMI within $7 \mathrm{~d}$ & $44(11)$ & $32(8)$ & .18 & -10.5 \\
\hline Previous PCI & $15(4)$ & $22(6)$ & .31 & 8.5 \\
\hline Nonelective case & $88(23)$ & $95(25)$ & .61 & 4.3 \\
\hline Active smoking & $69(18)$ & $60(16)$ & .44 & -6.3 \\
\hline Nonsmoker & $138(36)$ & $152(40)$ & .33 & 7.5 \\
\hline Dialysis preoperatively & $4(1)$ & $1(0)$ & .37 & -9.7 \\
\hline COPD & $16(4)$ & $16(4)$ & $>.99$ & 0.0 \\
\hline \multicolumn{5}{|l|}{ LVEF } \\
\hline$>65 \%$ & $100(26)$ & $111(29)$ & 一 & 6.4 \\
\hline $50 \%-65 \%$ & $151(39)$ & $149(39)$ & - & -1.1 \\
\hline $30 \%-49 \%$ & $105(27)$ & $96(25)$ & - & -5.3 \\
\hline$<30 \%$ & $16(4)$ & $12(3)$ & - & -5.6 \\
\hline Missing & $12(3)$ & $16(4)$ & .71 & - \\
\hline Left main $>60 \%$ & $72(19)$ & $78(20)$ & .65 & 3.9 \\
\hline No. of anastomoses & $3.4 \pm 0.7$ & $3.4 \pm 0.8$ & .12 & 0.0 \\
\hline 2 & $31(8)$ & $30(8)$ & - & -1.0 \\
\hline 3 & $207(54)$ & $195(51)$ & - & -6.3 \\
\hline$>3$ & $146(38)$ & $159(41)$ & .14 & 6.9 \\
\hline Intraoperative & $\begin{array}{c}\text { SITA + SV } \\
(\mathbf{n}=\mathbf{3 8 4})\end{array}$ & $\begin{array}{c}\text { TAR } \\
(\mathbf{n}=\mathbf{3 8 4})\end{array}$ & $\begin{array}{c}P \\
\text { value } \\
\end{array}$ & \\
\hline Bypass time (min) & $101.5 \pm 33.7$ & $99.6 \pm 26.9$ & .30 & \\
\hline Crossclamp time (min) & $74.9 \pm 23.5$ & $78.1 \pm 23.6$ & .33 & \\
\hline
\end{tabular}

\begin{tabular}{lccc}
\hline \multicolumn{1}{c}{ Early outcomes } & $\begin{array}{c}\text { SITA }+\mathbf{S V} \\
(\mathbf{n}=\mathbf{3 8 4})\end{array}$ & $\begin{array}{c}\text { TAR } \\
(\mathbf{n}=\mathbf{3 8 4})\end{array}$ & $\begin{array}{c}\boldsymbol{P} \\
\text { value }\end{array}$ \\
\hline 30-d mortality & $5(1.3)$ & $3(0.8)$ & .73 \\
Sternal infection & $3(0.8)$ & $3(0.8)$ & $>.99$ \\
Harvest site infection & $4(1)$ & $2(0.5)$ & .69 \\
Postoperative AMI & $4(1)$ & $2(0.5)$ & .69 \\
Postoperative stroke & $2(0.5)$ & $5(1.3)$ & .45 \\
Return for bleeding & $6(1.6)$ & $9(2.3)$ & .61 \\
Renal impairment or & $10(2.6)$ & $9(2.3)$ & $>.99$ \\
$\quad$ dialysis & $31(8.1)$ & $27(7)$ & .69 \\
Any adverse event & & &
\end{tabular}

$A M I$, Acute myocardial infarction; $C O P D$, chronic obstructive pulmonary disease $L V E F$, left ventricular ejection fraction; $P C I$, percutaneous coronary intervention; SITA, single internal thoracic artery; $S V$, saphenous vein; TAR, total arterial revascularization. 


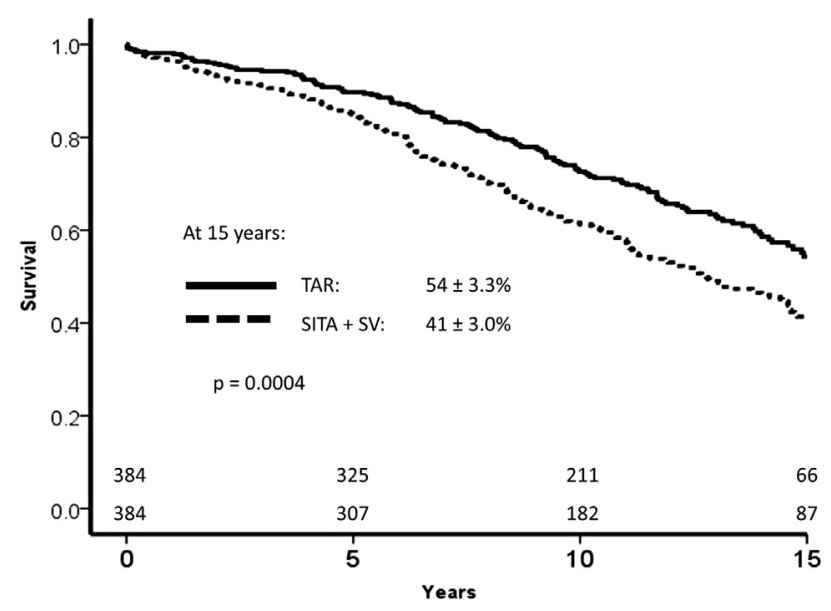

FIGURE 2. The 15-year survival among 384 propensity score matched patient pairs. SITA, Single internal thoracic artery; $S V$, saphenous vein; $T A R$, total arterial revascularization.

However, this risk is offset by the favorable qualities of the additional RITA. The ITAs are more resistant to atherosclerosis than SVs. The endothelium shows fewer fenestrations and lower permeability, a strong antithrombotic capability, greater endothelial nitric oxide production, and unique ways of reducing lipoprotein transfer and resistance of adhesion molecules, preventing inflammatory cells and smooth muscle cell proliferation. These latter changes, together with the small diameter of the ITA that creates better size matching with target vessels may contribute to its durability and resistance to arterial pressure. ${ }^{12}$

Indeed, RITA patency has been found in observational studies to be comparable to the LITA especially when used as an in situ conduit. ${ }^{13}$ In the current study, approximately half of our patients received in situ RITAs. It should be noted that our practice has evolved whereby early on, we performed in situ RITA to right coronary artery anastomoses, with disappointing results. Subsequently, we used the RITA as a free graft. More recently, however, we have deployed the in situ RITA to the left coronary system, thus incorporating the RITA as part of a BITA strategy. Studies suggest that the configuration of the RITA determines the patency of in situ RITAs, which may be superior to free grafts, although this remains contentious. ${ }^{7}$

The finding of multiple arterial grafting to be associated with improved survival is consistent with a recent analysis by Locker and colleagues ${ }^{14}$ from the Mayo Clinic. However, in that study, approximately one quarter of patients had 2vessel disease, and in the multiple arterial grafting group, BITA was used in $85 \%$ of cases with $50 \%$ of patients receiving at least $1 \mathrm{SV}$, suggesting the important prognostic benefit associated with BITA grafting. ${ }^{14}$ This current study, which includes only those with 3-vessel disease, BITAs were used in only $36 \%$ of the TAR group, raising speculation that RAs may indeed provide a prognostic benefit.
$\mathrm{He},{ }^{15}$ with experience in the pharmacology of vascular conduits, developed 2 antispasm protocols for arterial conduits. The verapamil/glyceryl trinitrate solution was used initially for vein grafts but was found to be effective for arterial grafts. Development of new generations of dihydropyridine calcium antagonists, such as nicardipine, has replaced verapamil and has been shown to relax both vasoconstrictor mechanisms, including depolarization and receptor functions.

The proposed superiority of arterial grafts may lie in their effect on the native circulation. Dimitrova and colleagues ${ }^{16}$ reported greater progression of native vessel disease when vein grafts were used. The fate of the native circulation, on which grafts rely for adequate run-off and collateralization, may be as important in outcome and survival as graft patency. The supra-physiologic flow provided by vein grafts may create turbulence that promoted progression of atherosclerotic disease.

We noted that crossclamp times were similar between the TAR and SITA + SV groups. Approximately 50\% of RITAs were used as free grafts, as were all radial grafts; therefore, the number of anastomoses in each arm was similar, and the clamp times are not significantly different. In cases in which an in situ RITA was used as the second arterial graft, one fewer anastomosis was required, but this may be offset by the other steps involved in such a maneuver, such as passing the RITA behind the thymic fat if an anterior crossover is used or through the transverse sinus in a posterior crossover, and the requirement to confirm absence of torsion, snagging of hemostatic clips, adequacy of length, and so forth, in performing this relatively demanding graft technique. The time taken for this is likely to have offset any time saved by the lack of a proximal anastomosis, making the clamp times similar in all configurations.

\section{Study Limitations}

Limitations of this study include its retrospective nature and the inability to account for unquantified factors, which may create the potential for hidden bias. Examples of this might include the frailty indices, the size or quality of the coronary targets, the severity of subtending stenoses, and the surgeon's experience level with a given conduit. Propensity scoring and creation of matched pairs necessarily cannot account completely for such bias. Furthermore, in this particular study we have not evaluated the impact of TAR in specific subgroups, such as those with diabetes, the elderly, and those poor left ventricular function, which will form the basis of future analyses.

\section{CONCLUSIONS}

This large multicenter observational study suggests that a strategy of TAR using ITAs and RAs is associated with improved survival compared with the use of only a single 
arterial graft and SV grafts. This may be secondary to the protective effects of arterial conduits or the deleterious sequelae of veins. We postulate that TAR eventually may be shown to yield a superior long-term clinical outcome, although strong evidence for this is currently lacking.

\section{References}

1. Buxton BF, Ruengsakulrach P, Fuller J, Rosalion A, Reid CM, Tatoulis J. The right internal thoracic artery graft-benefits of grafting the left coronary system and native vessels with a high grade stenosis. Eur J Cardiothorac Surg. 2000; 18:255-61.

2. Shah PJ, Bui K, Blackmore S, Gordon I, Hare DL, Fuller J, et al. Has the in situ right internal thoracic artery been overlooked? An angiographic study of the radial artery, internal thoracic arteries and saphenous vein graft patencies in symptomatic patients. Eur J Cardiothorac Surg. 2005;27:870-5.

3. Deb S, Cohen EA, Singh SK, Une D, Laupacis A, Fremes SE. RAPS Investigators. Radial artery and saphenous vein patency more than 5 years after coronary artery bypass surgery: results from RAPS (Radial Artery Patency Study). J Am Coll Cardiol. 2012;60:28-35.

4. Hayward PA, Buxton BF. The Radial Artery Patency and Clinical Outcomes trial: design, intermediate term results and future direction. Heart Lung Circ. 2011;20:187-92.

5. Goldman S, Sethi GK, Holman W, Thai H, McFalls E, Ward HB, et al. Radial artery grafts vs saphenous vein grafts in coronary artery bypass surgery: a randomized trial. JAMA. 2011;305:167-74.

6. Hayward PA, Gordon IR, Hare DL, Matalanis G, Horrigan ML, Rosalion A, et al. Comparable patencies of the radial artery and right internal thoracic artery or saphenous vein beyond 5 years: results from the Radial Artery Patency and Clinical Outcomes trial. J Thorac Cardiovasc Surg. 2010;139:60-5.

7. Taggart DP, D'Amico R, Altman DG. Effect of arterial revascularisation on survival: a systematic review of studies comparing bilateral and single internal mammary arteries. Lancet. 2001;358:870-5.

8. Australian Institute of Health and Welfare. National Death Index (NDI). 2013. Available at: https://www.aihw.gov.au/national-death-index/. Accessed April 30, 2013.

9. Austin PC. Propensity-score matching in the cardiovascular surgery literature from 2004 to 2006: a systematic review and suggestions for improvement. J Thorac Cardiovasc Surg. 2007;134:1128-35.

10. Borger MA, Rao V, Weisel RD, Ivanov J, Cohen G, Scully HE, et al. Deep sternal wound infection: risk factors and outcomes. Ann Thorac Surg. 1998;65:1050-6.

11. Taggart DP, Altman DG, Gray AM, Lees B, Nugara F, Yu LM, et al; ART Investigators. Randomized trial to compare bilateral vs single internal mammary coronary artery bypass grafting: 1-year results of the Arterial Revascularisation Trial (ART). Eur Heart J. 2010;31:2470-81.

12. Otsuka F, Yahagi K, Sakakura K, Virmani R. Why is the mammary artery so special and what protects it from atherosclerosis? Ann Cardiothorac Surg. 2013;2:519-26.

13. Tatoulis J, Buxton BF, Fuller JA. The right internal thoracic artery: the forgotten conduit-5,766 patients and 991 angiograms. Ann Thorac Surg. 2011;92:9-15.

14. Locker C, Schaff HV, Dearani JA, Joyce LD, Park SJ, Burkhart HM, et al. Multiple arterial grafts improve late survival of patients undergoing coronary artery bypass graft surgery: analysis of 8622 patients with multivessel disease. Circulation. 2012;126:1023-30.

15. He GW. Arterial grafts: clinical classification and pharmacological management. Ann Cardiothorac Surg. 2013;2:507-18.

16. Dimitrova KR, Hoffman DM, Geller CM, Dincheva G, Ko W, Tranbaugh RF. Arterial grafts protect the native coronary vessels from atherosclerotic disease progression. Ann Thorac Surg. 2012;94:475-81.

\section{Discussion}

Dr Joseph Sabik (Cleveland, Ohio). You and your colleagues should be commended for your persistent advocacy of the use of multiple arterial grafts in coronary surgery and for your continued investigation and reporting of their benefits in patients with ischemic heart disease. In this article, you found no short-term harm and better long-term survival in patients with 3-vessel disease who underwent TAR compared with those who received a SITA graft and vein graft.

My first question has to do with how many arterial grafts are enough? In your present analysis, you compared the outcomes of patients with 3 -vessel disease who received 1 arterial graft with vein graft with those who received 3 arterial grafts. What about the patients who received 2 arterial grafts and 1 vein graft? Was their survival similar to those receiving all arterial grafts or was it somewhere in the middle? As you are aware, it takes many years to demonstrate the benefit of 2 arterial grafts over just 1 in improving survival. Is the same true for 2 versus 3 ?

Dr Hayward. In answer to Dr Sabik's question about how many arterial grafts is enough, from our RA trial, where some patients have had multiple serial angiograms and we can track the progression of the native vessel disease, our data look similar to those of Robert Tranbaugh's group, and the addition of $1 \mathrm{SV}$ graft seems to be associated with an acceleration of native vessel disease. So perhaps even 1 vein graft prejudices outcome, if not survival. If so, it won't be by graft potency. I think it is more an issue of the acceleration of the native vessel disease.

Dr Sabik. You and your colleagues have been advocates of the RA in coronary surgery. In the total arterial group, almost all patients had at least 1 RA as a bypass graft, half had both RAs, and approximately one third had BITA grafting. In which patients do you use both ITAs and in whom would you rather use a SITA and both RAs?

Dr Buxton. That is a good question. Our philosophy in the earlier part of this program was that in patients aged more than 70 years we favored use a single LITA with the 2 RAs. As you saw from our data, we had a large number of bilateral RAs used that appeared to be well tolerated in the older group. More recently, we used BITA grafting in the elderly patients with few complications.

Dr Sabik. One of the limiting factors in using all arterial grafts is the detrimental effect of native coronary artery competitive flow an arterial graft patency. This is particularly true for patients with moderate obstruction, $50 \%$ to $70 \%$, especially in the right coronary. In these patients with moderate obstruction of the right coronary and you are planning on doing TAR, how do you revascularize the right?

Dr Buxton. Basically, in grafting the right coronary artery system, we use an RA if the stenosis was greater than $70 \%$.

Dr Sabik. Thank you, and congratulations.

Dr Domenico Paparella (Bari, Italy). One of the reasons why multiple arterial grafts are not commonly performed as should be and as has been said earlier in this session, it is because the operation is more technically demanding. In your propensity score, were you able to include the surgeon performing the operation, because probably those who did arterial revascularization were more experienced or more talented than the other groups?

Dr Buxton. Well, I think if you do a large number of arterial graft procedures, it becomes a reasonably standard operation similar to that of a SITA and SV grafts. In fact, the timing is not that different. It is only a little more difficult if 2 thoracic arteries and 2 RAs are used, because the operating time is longer. I find it hard to encourage the young surgeons to perform multiple arterial 
grafts. Many choose the easier option of 1 radial, 1 thoracic, and 1 vein graft.

Dr Claudio Muneretto (Brescia, Italy). As you know, in the last few years there are many contradictory reports that jeopardize the use of the RA, probably because the coronary RA is sensitive to target location and target stenosis, and results could be jeopardized because the inlet may be a risk factor if you anastomose the artery to the aorta or you use the artery as a composite arterial graft. Now after so many years of experience, what do you suggest as the inlet of the RA, the aortic anastomosis or a composite arterial graft, and how do you select patients in relation to target location and target stenosis?
Dr Buxton. For the proximal site of the radial, we usually take it off the aorta, because we don't like anastomosing a 3- to 4-mm diameter RA with a 2-mm LAD artery, for several reasons. First, it is not a good match, and second, if there is any damage to the LITA as a result, the patient may suffer. So we attach it to the aorta rather than fashioning a composite graft.

Dr Muneretto. Yes. Any comments about target location and target stenosis?

Dr Buxton. We accept a native artery stenosis greater than $70 \%$. But other surgeons, like Steve Fremes and his group, prefer a $90 \%$ stenosis before using the RA because of their concern about competitive flow.

\title{
EDITORIAL COMMENTARY
}

\section{Total arterial revascularization: When will its time come?}

\author{
Todd K. Rosengart, MD, FACS
}

Myocardial revascularization incorporating the exclusive use of arterial conduits remains stubbornly shunned by the cardiac surgery community despite a growing body of evidence that "total arterial revascularization" yields superior long-term survival results than coronary bypass incorporating saphenous vein grafts. For example, as recently as 2009 , only $4 \%$ of coronary bypass procedures reported in the Society of Thoracic Surgeons database include the use of bilateral internal thoracic artery grafts. ${ }^{1}$

In this issue of the Journal, Buxton and colleagues ${ }^{2}$ add to the growing body of evidence supporting the long-term benefits of total arterial revascularization. They report a study cohort of approximately 3800 patients who underwent coronary bypass surgery from 1995 to 2010 and show that the patients who received total arterial revascularization had 30\% superior long-term survival than the patients who underwent a single in situ internal thoracic artery and saphenous vein grafting. More specifically, in a 384 matched patient pair propensity score subset, they observed that the patient survival at 15 years was greater after total arterial revascularization than after internal

From the Baylor College of Medicine, Houston, Tex.

Disclosures: Author has nothing to disclose with regard to commercial support.

Received for publication Aug 19, 2014; accepted for publication Aug 20, 2014

Address for reprints: Todd K. Rosengart, MD, FACS, Michael E. DeBakey

Department of Surgery, Baylor College of Medicine, One Baylor Plaza, BCM

MS 390, Houston, TX 77030 (E-mail: todd.rosengart@bcm.edu

J Thorac Cardiovasc Surg 2014;148:1244-5

$0022-5223 / \$ 36.00$

Copyright (c) 2014 by The American Association for Thoracic Surgery

http://dx.doi.org/10.1016/j.jtcvs.2014.08.036 thoracic artery plus saphenous vein grafting $(54 \%$ vs $41 \% ; P=.0004)$. These data would seem to support an evidence-based shift in practice that even the most steadfast arterial conduit skeptic should have difficulty in refuting, but recent clinical practice trends do not encourage such expectations.

Other recent articles demonstrate similar benefits associated with arterial grafting. The Cleveland Clinic outcomes article by Raza and colleagues, ${ }^{3}$ also in this month's Journal, shows that bilateral late mortality at 7.8 years median follow-up was $21 \%$ less in patients who received bilateral internal thoracic artery grafts than in patients who received single internal thoracic artery grafts. Similar term follow-up data from Saswata and colleagues ${ }^{4}$ likewise demonstrated an approximately $50 \%$ reduction (odds ratio, $0.43 ; 95 \%$ confidence interval, $0.25-0.75 ; P=.003$ ) in graft occlusion rates for radial artery. In this context, it is important to ask why these data are not affecting "real world" clinical practices, for until these obstacles are understood, it is unfortunately not reasonable to anticipate in the foreseeable future the changes in clinical practice seemingly mandated by this evidence.

The first and perhaps greatest issue in advancing this agenda has to be a consideration of data quality. As it has occurred in other areas to which changes to long-standing and previously well-accepted practices have been proposed, skepticism may well trump reason in the absence of "gold standard" prospective randomized control trials. The arena of total arterial revascularization unfortunately has not enjoyed the benefit of great amounts of such data. As a 